CyberSpace

\title{
Safe and effective use of medications: a global concern
}

Compiled by A L Scheffler

Medication safety goes global Ulrich Beck, the German sociologist, has argued that we live in a "global risk society". Perhaps nowhere is this quintessentially postmodern assertion more true than in the area of medication safety which is now - or arguably should be-a priority health policy issue for all countries. This issue of CyberSpace highlights a selection of useful resources on mitigating the hazards and maximizing the benefits from human medicines.

\section{Uppsala Monitoring Centre (UMC)}

The UMC (also known as the WHO Collaborating Centre for International Drug Monitoring) in March 2002 published an impressive non-technical booklet, "Viewpoint Part 1: Issues, controversies and science in the search for safer and more rational use of medicines" (http://www.who-umc.org/publ.html). The booklet raises (on page 21) the issue of whether traditional "pharmacovigilance" (drug safety monitoring) practices are too narrowly construed. In the past, pharmacovigilance "has been seen as a relatively limited-though important-technical activity concerned with the identification of adverse drug reactions from pharmaceutical products. Its uses have been more or less confined to regulatory deliberations and decisions". But, according to the UMC, "it is now seen as the starting point for the consideration of larger and more radical questions: the benefit, harm, effectiveness and risk of medicinal products as they affect individual patients and public health; ... . the rational use of drugs in collaborative relationships with patients; [and] the communication of complex issues among healthcare professions and with the media, patients and the public at large". (Viewpoint Part 2 will be published later.)

The UMC is part of the World Health Organization's quality assurance and safety of medicines activities (see http:// www.who.int/medicines/organization/qsm/orgqsm.shtml). Through the UMC, the WHO is challenging all stakeholders to collaborate across national, disciplinary, and status boundaries to reduce negative impacts from unsafe use of medicines. According to its website, the WHO is "in the process of establishing a highlevel advisory committee on the safety of medicinal products".

Communication is key In a May 2002 article entitled "Effective communication of drug safety information to patients and the public: a new look" (Drug Safety, Volume 25, No 5, pp 313-21; abstract available at http://www.ingenta.com//, Dr Eleanor $M$ Vogt also attempts to reframe the process of communicating drug risk/benefit information. The key question, she writes, is "how do we provide an equal voice for patients with the other stakeholders in the determination and communication of benefit-risk information?" This will be accomplished when certain principles from risk communication research and general systems theory are recognized and accepted. Such principles include "the expertise for determining acceptable benefit and risk is dispersed throughout society" and "patients must be involved in the continuous feedback and redesign of the evolving drug safety information system".

Dr Vogt also co-chaired a March 2000 workshop organized by the National Patient Safety Foundation and the US Food and Drug Administration entitled "Safe Medical Treatments: Everyone Has a Role" (http://www.fda.gov/cder/calendar/meeting/ npsf2000/default.htm). One outgrowth of that workshop is a draft consumer brochure from the "Partnership for Safe Medication Use" called "Think it Through . . . A Guide to Managing the Benefits and Risks of Medicines" which, at the time of writing, has not been publicly released. It should eventually appear with other listed publications at http://www.fda.gov/cder/ consumerinfo/DPAdefault.htm.

Erice Declaration The current global movement to reposition drug safety as an urgent public health issue can in part be traced back to "The Erice Declaration on Communicating Drug Safety Information" published in September 1997 (http:// www.who-umc.org/publ.html\#Erice). "Drug safety information must serve the health of the public", it states. "Education in the appropriate use of drugs, including interpretation of safety information, is essential for the public at large, as well as for patients and healthcare providers. . . . Every country needs a system with independent expertise to ensure that safety information on all available drugs is adequately collected, impartially evaluated, and made accessible to all."

IT to the rescue? Major players in the US healthcare industry met in June 2002 to launch the National Alliance for Health Information Technology (http://www.nahit.org/). Topping the Alliance's early agenda is agreeing voluntary standards for applying bar code labels to medication and biological product packaging. The Alliance states it will also work with the US Food and Drug Administration (FDA) as that agency develops its bar code label regulations. The FDA was to hold a public hearing on the regulations on 26 July 2002 (detailed notice at http://frwebgate.access.gpo.gov/cgi-bin/getdoc.cgi? dbname $=2002$ register\&docid $=02-15208$-filed.pdf; corrections at http://www.fda.gov/OHRMS/DOCKETS/98fr/ 062602c.htm)

Quick takes Nurses warned on 'crushing' tablets [UK] BBC Health News, 3 July 2002 (http://news.bbc.co.uk/hi/ english/health/newsid_2088000/2088133.stm)

Health Canada targets postmarket surveillance of drugs - Can Med Assoc J 11 June 2002 (http://www.cmaj.ca/cgi/content/ full/166/12/1580)

Doctors tackle medication misuse [Indonesia] - BBC Health News, 2 June 2002 (http://news.bbc.co.uk/hi/english/ health/newsid_2018000/2018228.stm)

Drugs agency [EMEA] reminds companies of duty to report side effects - BM 20 April 2002 (http://bmi.com/cgi/content/full/ $324 / 7343 / 938 / b$ )

"The use of medications always carries with it a risk - the magnitude of the risk being largely a function of the product itself (e.g. its toxic power), the manner in which it is taken (e.g. frequency, route, dose, dosage form), and the conditions under which it is consumed (e.g. with other medications, alcohol, foods, or disease problems. .. . The paradox of medications, which can heal or cause great harm, demands that their properties be understood 
and that they be used safely". Manasse HR. The paradox of medication use. In: Zipperer L, Cushman S, eds. Lessons in Patient Safety. Chicago: National Patient Safety Foundation, 2001, p 73. (Book available at http://www.npsf.org/forms/orderform. html\#publications.)

"Given current scientific and medical knowledge, it is not possible to learn everything about the effects of a medical product. For example, new information about long-marketed products may become available. Therefore, a degree of uncertainty always exists about both the benefits and risks of medical products, including unexpected side effects, long-term effects, effects of offlabel use, and effects in populations not studied before marketing". Medical product safety. In: Healthy People 2010. US Department of Health and Human Services, 2000; Chapter 17. (http://web.health.gov/healthypeople/document/HTML/ Volume2/17Medical.htm.)

About the author Adam L Scheffler is an independent journalist, policy researcher, and social worker based in Chicago, Illinois.
Competing interests The author worked with Dr.

Eleanor M. Vogt in 1998 and 1999 while they both were with the National Patient Safety Foundation (http://www.npsf.org/), and provided research assistance for her May 2002 Drug Safety article discussed above. Mr Scheffler also co-authored a chapter in Lessons in Patient Safety, the book from which he drew the H R Manasse quotation above.

Broken links CyberSpace verifies that all featured web links (URLs) are working prior to publication. Please let us know about any broken links you encounter in this issue.

A L Scheffler Chicago, Illinois, USA a-scheffler-1@alumni.uchicago.edu 